\title{
Perceived stressors of oral hygiene students in the
}

\section{dental environment}

N A Gordon, ${ }^{1}$ DipOH, BA, MPH, Dip Adult Education; C A Rayner, ${ }^{1}$ DipOH, BA Hons, MA; V J Wilson, ${ }^{2}$ BChD, MChD;

K Crombie, ${ }^{3}$ Dip Diagnostic Radiography, HDE, MSc Dent; A B Shaikh, ${ }^{4}$ BChD, MSc Dent, MChD; S Yasin-Harnekar, ${ }^{5}$ BChD, MSc Dent, PDD

${ }^{1}$ Department of Oral Hygiene, Faculty of Dentistry, University of the Western Cape, Cape Town, South Africa

${ }^{2}$ Department of Restorative Dentistry, Faculty of Dentistry, University of the Western Cape, Cape Town, South Africa

${ }^{3}$ Department of Diagnostics and Radiology, Faculty of Dentistry, University of the Western Cape, Cape Town, South Africa

${ }^{4}$ Department of Orthodontics, Faculty of Dentistry, University of the Western Cape, Cape Town, South Africa

${ }^{5}$ Department of Paediatric Dentistry, Faculty of Dentistry, University of the Western Cape, Cape Town, South Africa

Corresponding author: C A Rayner (crayner@uwc.ac.za)

Background. University students are exposed to a multitude of stressors that may impact on their performance. The nature of health sciences education generally involves early engagement with patients and communities, which may add to the stressors inherent to university life. There is sparse information on stressors in the oral hygiene educational environment.

Objective. To determine perceived stressors and the level of burnout among oral hygiene students at the University of the Western Cape, Cape Town, South Africa.

Method. A descriptive, cross-sectional study design was used. The study sample included all students in the Bachelor of Oral Health (BOH) degree during 2012 $(N=89)$. A self-administered questionnaire was used to gather data. Three parameters were measured, i.e. (i) demographic characteristics; (ii) perceived sources of stress, using a modified Dental Environment Stress (DES) questionnaire; and (iii) burnout, using the Maslach Burnout Inventory (MBI).

Results. Respondents were mostly female (74\%) and primarily in the 18 - 25-year age group (92\%). First- and 2nd-year students identified fear of failing and study load as major stressors. Stressors related to a lack of basic needs were identified as major stressors by $25 \%$ of 1 st-year students. Third-year students identified clinical quotas, supervision and patients being late as major stressors. MBI scores indicated that students were not at risk for burnout; however, most students (66.2\%) scored high on emotional exhaustion (EE).

Conclusion. Oral hygiene students identified stressors in their learning environment. There was a progressive increase in EE across academic years. The results suggest that interventions should be tailored for specific academic year groups.

Afr J Health Professions Educ 2016;8(1):20-24. DOI:10.7196/AJHPE.2016.v8i1.422

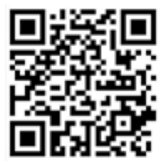

Stress is part of daily life and may be the stimulus for individual achievement. Therefore, stress can serve as a motivational factor for students to perform at their peak or reduce their level of effectiveness. ${ }^{[1]}$ Individuals experience stress to a greater or lesser degree, depending on their perception of the demands in their environment and the resources to cope with these demands. ${ }^{[2]}$

University entry for students is a transitional period, as they are exposed to a multitude of changes in their personal, social and academic environment. Conditions and events inherent to university life induce experiences of stress, which may lead to difficulty in adjusting to this new environment. ${ }^{[3]}$ The health sciences educational milieu is unique, as students are exposed to further stressors such as early engagement with patients and communities. Stress among students in various disciplines in the health sciences is well documented. ${ }^{[1,4-21]}$ However, the literature on stressors among students and qualified dental hygienists is sparse. ${ }^{[7,14,20-22]}$

Sources of environmental stress among dental students have been identified and quantified by means of the Dental Environment Stress (DES) questionnaire. ${ }^{[4,5]}$ Stressors identified include the learning environment, fear of failure, heavy workload, difficulty in dealing with patients, performing non-reversible procedures in a confined space, difficulty in dealing with transitions in curricula and difficult relationships with academic staff. Gorter et al. ${ }^{[11]}$ suggested that stress among dental students has been reported at length and that it would currently be more useful to focus on interventions to address this concern.

Long-term exposure to stress in the learning and working environment may result in burnout, ${ }^{[23]}$ also referred to as a syndrome found among professionals doing 'service work. ${ }^{\text {'24] }}$ Burnout includes the domains of emotional exhaustion (EE), becoming emotionally exhausted; depersonalisation (DP), the development of a negative, cynical attitude to patients; and a sense of diminished personal accomplishment (PA), evaluating oneself and one's own accomplishments negatively. Roberts and Ellingson ${ }^{[20]}$ reported that signs and symptoms of burnout include 'emotional, cognitive, behavioural and physical aspects. These may be seen as loss of humour, a persistent sense of failure, anger, resentment and bitterness, postponement of contact with patients, constant feeling of tiredness, increased use of sick leave, rigid thinking, and difficulty concentrating. ${ }^{[25]}$ Although burnout has not been reported as being prevalent, EE, the key dimension of burnout, has been reported among students and professionals in the dental field. ${ }^{[7,11,14,15,23,26]}$

There are no published reports on stress among South African (SA) oral hygiene students. As qualifications in both oral hygiene and dentistry are offered at the Faculty of Dentistry, University of the Western Cape (UWC), Cape Town, SA, it would be premature to develop student interventions without identifying the stressors and their effect.

The objective of this study was to determine perceived stressors and the level of burnout among oral hygiene students at UWC. 


\section{Methods \\ Study design}

A descriptive, cross-sectional study design was used.

\section{Study population}

All students registered for the 3-year Bachelor of Oral Health (BOH) programme during 2012 were included $(N=89)$.

\section{Instrument and data collection}

Data were collected by means of a self-administered questionnaire. The following three parameters were measured: $(i)$ demographic characteristics; (ii) perceived sources of stress, using a modified DES questionnaire; and (iii) burnout, using the Maslach Burnout Inventory (MBI). The DES ${ }^{[4]}$ and $\mathrm{MBI}^{[24]}$ questionnaires are validated instruments. Demographic characteristics included home language as a proxy of ethnicity, in view of the 11 official languages in SA.

The DES consisted of 79 statements categorised into the following areas of study: study environment $(n=27)$, theoretical aspects $(n=14)$, preclinical aspects $(n=13)$, and clinical aspects $(n=25)$. Students were asked to respond to each statement by indicating whether it posed 'no problem,' 'a small problem' or 'a huge problem' that might interfere with their studies. The following statements were added to suit the local context: discrimination due to race, nationality, gender or social class; transport to the university; accommodation; safety; and having enough food to eat.

The MBI consisted of 22 statements. Each statement was scored on a 7-point Likert scale ranging from 0 ('never' experienced) to 6 (experienced 'every day'). The MBI was divided into three subscales, i.e. EE, PA and DP. Statements in the MBI were adapted to include 'other students or people'. This was in view of the teaching methodologies that encompass engagement with students and communities throughout the programme.

The questionnaire was piloted with 10 students to assure validity, and modified accordingly. It was distributed to students for completion in their classrooms. Completed questionnaires were submitted to the researchers. The study was conducted at the end of the first semester.

\section{Data analysis}

Data were entered and analysed using descriptive statistics (IBM SPSS Statistics for Windows, Version 21.0, USA: IBM Corp.). Frequency distributions were used to identify stressors posing a 'huge problem' to students. The MBI manual ${ }^{[24]}$ was used to categorise the student groups into high, average and low risk for burnout. Burnout is indicated in high scores of EE $(\geq 27)$ and DP $(\geq 10)$ and low scores of PA $(\geq 40)$ in the Human Services Survey (MBI HSS). ${ }^{[24]}$

\section{Ethical considerations}

Ethical approval was obtained from the Faculty of Dentistry and University Research and Ethics committees, UWC. Prior to distributing the questionnaires, students were informed verbally and in writing of the purpose of the study. Informed consent was obtained.

\section{Results \\ Demographics}

The response rate was $85 \%$. Respondents were mostly female $(74 \%)$ and primarily in the 18 - 25-year age group (92\%). Six of the 11 official languages were reported as home languages, with 38\% having English, the medium of education at the university, as their home language.

More than half $(58 \%)$ resided in the Western Cape - the province where UWC is located; $76 \%$ had attended public schools and $24 \%$ private schools; $47 \%$ lived with families and the remainder stayed in university residences $(30 \%)$ or private residences $(17 \%)$.

\section{Student response to the DES statements}

Table 1 illustrates the top five stressors reported as a 'huge problem' for each category of the DES. The 'study environment' scored lowest overall of the four categories. Only 3rd-year students completed the clinical category and the majority experienced this as a 'huge problem.

Table 2 illustrates the top five stressors by year group, indicating that stressors vary across the academic years. First- and 2nd-year students identified the theoretical aspect of their studies as most stressful, whereas the 3 rd-year group reported the clinical category as most stressful.

Table 1 . The top five perceived stressors in each category of the DES

\begin{tabular}{|c|c|}
\hline Perceived stressors & $\begin{array}{l}\text { Responses to a } \\
\text { 'huge problem', \% }\end{array}$ \\
\hline \multicolumn{2}{|l|}{ Study environment } \\
\hline 1. Fear of being unemployed in future & 48 \\
\hline 2. Lack of time for relaxation & 37 \\
\hline 3. Neglect of personal life & 36 \\
\hline 4. Treated as being immature & 36 \\
\hline 5. Lack of confidence to be a successful hygienist & 34 \\
\hline \multicolumn{2}{|l|}{ Theoretical problems } \\
\hline 1. Heavy study load & 65 \\
\hline 2. Fear of failing a module or year & 64 \\
\hline $\begin{array}{l}\text { 3. Overloaded feeling due to the large number of } \\
\text { modules in the programme }\end{array}$ & 61 \\
\hline $\begin{array}{l}\text { 4. Having a lecture or clinic before a scheduled } \\
\text { assessment }\end{array}$ & 52 \\
\hline 5. Lack of self-motivation to study & 36 \\
\hline \multicolumn{2}{|l|}{ Preclinical problems (BOH II and III) } \\
\hline 1. Fear of making mistakes & 61 \\
\hline 2. Lack of time to practise preclinical procedures & 59 \\
\hline $\begin{array}{l}\text { 3. Limited co-operation from laboratory } \\
\text { technicians/staff }\end{array}$ & 54 \\
\hline 4. Meeting preclinical requirements & 51 \\
\hline $\begin{array}{l}\text { 5. Number of supervisors in relation to students; } \\
\text { inconsistency between supervisors }\end{array}$ & 46 \\
\hline \multicolumn{2}{|l|}{ Clinical problems (BOH III only) } \\
\hline 1. Number of assigned quotas & 95 \\
\hline $\begin{array}{l}\text { 2. Number of clinical supervisors in relation to } \\
\text { number of students }\end{array}$ & 74 \\
\hline 3. Fear of being criticised & 74 \\
\hline 4. Patients being late/missing appointment & 74 \\
\hline $\begin{array}{l}\text { 5. Fear of being unable to catch up with clinical } \\
\text { requirements }\end{array}$ & 74 \\
\hline
\end{tabular}


Table 2. Top five perceived stressors of the DES per year group

\begin{tabular}{|c|c|c|}
\hline Study year & Potential stressor & Frequency, $\%$ \\
\hline \multirow[t]{5}{*}{$\mathrm{BOH} \mathrm{I}$} & Fear of failing a module & 61 \\
\hline & $\begin{array}{l}\text { Overloaded feeling due to large number of } \\
\text { modules }\end{array}$ & 55 \\
\hline & Heavy study load & 52 \\
\hline & Fear of being unemployed in the future & 44 \\
\hline & Having financial responsibilities & 38 \\
\hline \multirow[t]{5}{*}{$\mathrm{BOH}$ II } & Heavy study load & 91 \\
\hline & $\begin{array}{l}\text { Overloaded feeling due to large number of } \\
\text { modules }\end{array}$ & 82 \\
\hline & Fear of failing a module or year & 77 \\
\hline & Having a lecture before an assessment & 68 \\
\hline & Fear of making mistakes & 66 \\
\hline \multirow[t]{5}{*}{ BOH III } & Number of assigned clinical quotas & 95 \\
\hline & $\begin{array}{l}\text { Number of clinical supervisors in relation } \\
\text { to students }\end{array}$ & 74 \\
\hline & Fear of being criticised by supervisors & 74 \\
\hline & Patients being late/missing appointments & 74 \\
\hline & $\begin{array}{l}\text { Fear of being unable to catch up with clinical } \\
\text { requirements }\end{array}$ & 74 \\
\hline
\end{tabular}

Although not in the top five stressors, the statements added to the DES questionnaire to suit the local context indicated the following: 1st-year students reported transport (29\%) and safety $(27 \%)$ to and from the university, accommodation (29\%), not being able to study in their living environment (24\%) and not having enough to eat (24\%) as a 'huge problem'. Discrimination due to race, nationality, gender or social class was reported as a 'huge problem' by 2 nd-year (32\%) and 3rd-year (37\%) students.

\section{Student response to the MBI}

Table 3 shows overall means and standard deviations for EE, PA and DP. The mean and standard deviations for individual statements were ranked in descending order. Statements referring to 'self' were reportedly experienced more frequently in EE ('I feel used up at the end of my day at university') and DP ('I worry that my studies are hardening me emotionally') subscales.

Table 4 shows the categorisation of year groups according to their risk for burnout. The means and standard deviations of the MBI score for each subscale and the percentage of students in the respective year group are indicated. Most (66.2\%) students scored high on EE, the key dimension for burnout. However, there were significant differences between the three year groups ( $p=0.039$ ). In terms of burnout, 1 st-year scores were seen as 'indicative of engagement with work', with $76.5 \%$ of the class scoring high on PA and $14.7 \%$ scoring average on EE. Second-year scores were high on EE and DP but average on PA, suggesting a risk for burnout. Third-year scores showed a reversal on the DP and PA scores; yet, EE remained high.

There was no significance in student demographics and EE, DP and PA. There was considerable variation in student experiences in the academic year groups, as seen by the percentage of students in each category.

\section{Discussion \\ Demographic characteristics}

Oral hygiene is a predominantly female-orientated profession globally. ${ }^{[27]}$ The gender distribution in this study is indicative of a changing student
Table 3. The Maslach Burnout Inventory

\begin{tabular}{ll}
\hline Statements describing student feelings & Mean (SD) \\
\hline Emotional exhaustion & $3.28(1.75)$ \\
1. I feel used up/worn out at the end of a day at university & $4.25(1.53)$ \\
2. I feel emotionally drained/exhausted from my studies & $4.24(1.56)$ \\
3. I feel fatigued/tired when I get up in the morning and & $4.11(1.63)$ \\
have to face another day at university & \\
4. I feel frustrated by my studies & $3.96(1.65)$ \\
5. I feel burnt out from my studies & $3.86(1.65)$ \\
6. I feel that I am working too hard on my studies & $3.01(1.94)$ \\
7. I feel that I am at the end of my rope & $2.32(2.23)$ \\
8. Interacting with people all day is really a strain for me & $1.96(1.84)$ \\
9. Interacting with people directly puts too much stress on me & $1.85(1.74)$ \\
Depersonalisation & $1.29(1.58)$ \\
1. I worry that my studies are hardening me emotionally & $2.53(2.19)$ \\
2. I have become more callous/uncaring towards people & $1.35(1.82)$ \\
since I started my studies & \\
3. I feel that I treat some patients and other students as if & $0.99(1.35)$ \\
they were impersonal objects &
\end{tabular}

4. I don't really care what happens to some patients and 0.93 (1.44) other students

5. I feel that patients and other students blame me for some $\quad 0.65(1.12)$ of their problems

Personal achievement

1. I feel I'm positively influencing other people's lives through my studies

2. I can easily create a relaxed atmosphere with my patients 4.17 (1.63) and other students

3. I can easily understand how my patients and other students feel about things

4. I feel exhilarated/inspired after working closely with my patients and other students

5. I deal very effectively with the problems of my patients and other students

6. I have accomplished many worthwhile things in my studies 3.68 (1.70)

7. In my studies, I deal with emotional problems very calmly 3.47 (1.74)

8. I feel very energetic

$2.85(1.70)$

profile, with more males entering the profession. Further diversity of the study population is evident in the home language distribution and schooling background.

Bojuwoye $^{[3]}$ reported that factors associated with financial difficulties, demands of the university environment and administrative processes were experienced as stressful by 1st-year university students. The current study suggests that 1st-year oral hygiene students may experience similar stressors. Reports of discrimination due to race, nationality or gender as a huge problem' are cause for concern and warrant further enquiry. The decision to include additional stressors to the DES was supported by the results, suggesting that a validated tool should be adapted to the local context to accommodate the social, cultural, economic and historical factors. 
Table 4. Categorisation of MBI subscales by student year group, BOH

\begin{tabular}{lllll}
\hline MBI subscales & Overall score & 1st year & 2nd year & 3rd year \\
\hline EE category & High & Average & High & High \\
EE score & $29.04(11.00)$ & $25.79(10.56)$ & $33.09(10.10)$ & $30.16(11.51)$ \\
\% within group & 66.2 & 14.7 & 81 & 63.2 \\
DP category & Average & Low & High & Average \\
DP score & $6.28(5.24)$ & $5.14(4.97)$ & $8.13(4.86)$ & $6.15(5.77)$ \\
\% within group & 27.8 & 56.3 & 36.4 & 27.8 \\
PA category & High & High & Average & High \\
PA score & $28.89(8.23)$ & $29.02(10.05)$ & $26.44(6.35)$ & $31.47(5.66)$ \\
\% within group & 76 & 76.5 & 13.6 & 63.2
\end{tabular}

\section{Student response to the DES statements}

There were a number of similarities between the top stressors identified in this study and those in the international literature. ${ }^{[1,3-5,9,10,12,13,16,17]}$ The study load, financial responsibilities, patients being late or missing appointments, and fear of being unable to catch up with clinical requirements were also noted among US dental hygiene students. ${ }^{[20]}$ At least two stressors in the top five of each component of the DES questionnaire posing a 'huge problem' in this study were also reported by Saudi Arabian dental students. ${ }^{[4]}$ These stressors were: lack of time for relaxation, being treated as immature, study load, feeling overloaded due to the large number of modules in the programme, lack of time to practise a preclinical procedure, number of supervisors in relation to students, inconsistency between supervisors, fear of being criticised, and patients being late or missing appointments (Table 1). Fijian dental students also reported the following stressors: feeling overloaded, fear of failure, criticism from clinical supervisors in the presence of patients, amount of assigned work, financial resources, and fear of unemployment after graduation. ${ }^{[12]}$ Of concern is that stressors identified by Garbee et al. ${ }^{[1]}$ in 1980 are still reported in the current literature and were also found in our study. Considering that the stressors were known, the authors questioned whether demands by departments were realistic and in the interest of students or whether departments competed for students' time. ${ }^{[1]}$ Stressors in the abovementioned studies could be categorised as student, staff, curriculum and/or educational system related. It may be expedient to use categories to guide universities to the type and level of intervention required for a less stressful dental environment.

Final-year oral hygiene students reported significantly higher $(p<0.01)$ stress levels than 1st-year students in three DES items, i.e. atmosphere created by clinical faculty, lack of input into decision- making processes at the faculty and inconsistency of feedback between different instructors. ${ }^{[20]} \mathrm{A}$ number of items identified were also noted by students in the current study. The authors questioned whether different experiences to stressors between class years were a result of changing demands of the programme or the unique personality of a class. ${ }^{[20]}$ The results of this study did not indicate a lack of input into decision-making processes at university as a 'huge problem', contrary to those reported by Roberts and Ellingson. ${ }^{[20]}$ A possible explanation is that UWC students have representation on faculty structures.

The manner in which stress is defined by the researcher informs the research approach and ultimately the answers gained. Hamill, ${ }^{[28]}$ in a qualitative study of student nurses' perceptions of stress, used Cox's interactionist model of stress. This model advocates that 'stress should not be seen as either a stimulus or a set of responses but rather a person's interpretation of the significance of a threatening event (the stimulus) and his or her resources to cope with it (the response)'. The DES and MBI questionnaires are quantitative instruments and may not be useful on their own. Future studies using these instruments should consider using a mixed-method approach, where qualitative aspects are included to allow for clarification and elaboration of student experiences.

Polychronopoulou and Divaris ${ }^{[16]}$ grouped stressors into seven categories to facilitate targeted interventions. These are self-efficacy beliefs, faculty and administration, workload, patient treatment, clinical training, performance pressure, and other. A substantial number of stressors identified by students in this study were in the 'self-efficacy beliefs' category, suggesting that further enquiry may be needed. In considering interventions, programmes may also have limited control over stressors, such as patient co-operation, ${ }^{[20]}$ also identified as a stressor in this study. In such instances student stress can be reduced through training to develop interpersonal relationships with patients to foster understanding of the patient's life context and so improve co-operation. ${ }^{[20]}$

Longitudinal studies have been suggested to better the understanding of stressors identified and to monitor at-risk students to inform appropriate interventions. ${ }^{[11,12,21,23,29]}$ This position is supported by the current study in view of stressors appearing to vary across the academic years.

\section{Response to the MBI}

The scores for each subscale of the MBI show a trend (Table 3), with statements referring to 'engagement with others' reported at a lower frequency on the $\mathrm{EE}$ and DP subscales and at a higher frequency on the PA subscales. This observation suggests that students may feel better about themselves when interacting with others, which supports the view that early engagement with patients is 'protective' in terms of stress and burnout. ${ }^{[19]}$ The opposite, where engagement with 'self' was reported at a higher frequency on $\mathrm{EE}$ and a lower frequency on PA, may indicate that students are challenged to cope in an academic environment. This finding may be consistent with the fact that a number of stressors noted in the DES were located in the 'self-efficacy beliefs' category. ${ }^{[16]}$

The overall scores (Table 4) indicate that the group is not at risk of burnout. Although the mean scores for the programme may be favourable, considerable variations across the academic years were noted. The 1st-year class started off positively, showing 'engagement with work', the 2nd-year class appeared to be at risk of burnout, and at the 3rd-year level students appeared to be coping better. Of concern is that $\mathrm{EE}$, the key dimension of burnout, increased progressively over the 3 academic years, with $62 \%$ of students falling into the 'high' category in the 3rd year. Dimensions of burnout were also found among qualified dental hygienists, with high levels of EE (14\%) and DP (15\%) and high levels of diminished PA (29\%). ${ }^{[14]}$ Hinshaw et al. ${ }^{[7]}$ reported on stress and burnout experienced by dental hygiene educators. The authors highlighted institutional responsibility to reduce stress experienced as a result of educators' roles and responsibilities.

The results of this study cannot be generalised with regard to the broader oral hygiene student 
population. However, the findings provide insight into the perceptions and experiences of UWC oral hygiene students.

\section{Conclusion}

This study found that stressors were identified within the oral hygiene student population. Stressors were generally similar to those reported by dental hygiene and dental students in the international literature. The fact that $\mathrm{EE}$ increased progressively across the 3 years indicated a need for intervention to improve the experiences of students in the dental learning environment.

The results suggest that interventions should address student stressors at a generic student level and at the level of the academic year.

\section{References}

1. Garbee WH, Zucker SB, Selby GR. Perceived sources of stress among dental students. J Am Dent Assoc 1980;100:853-857. [http://dx.doi.org/10.14219/jada.archive.1980.0279]

2. Taylor SE. Health Psychology. 3rd ed. New York: McGraw-Hill, 1995.

3. Bojuwoye O. Stressful experiences of first year students of selected universities in South Africa. Counselling Psychology Quarterly 2002;15(3):277-290.

4. Al-Saleh SA, Al-Madi EM, Al-Angari NS, Al-Shehri HA, Shukri MM. Survey of perceived stress-inducing problems among dental students, Saudi Arabia. Saudi Dent J 2010;22:83-88. [http://dx.doi.org/10.1016/j.sdentj.2010.02.007] 5. Alzahem AM, van der Molen HT, Alaujan AH, Schmidt G, Zamakhshary MH. Stress amongst dental students: A systematic review. Eur J Dent Educ 2011;15:8-18. [http://dx.doi.org/10.1111/j.1600-0579.2010.00640.x]

6. Dahan $\mathrm{H}$, Bedos C. A typology of dental students according to their experience of stress: A qualitative study. 6. Dahan H, Bedos C. A typology
Dent Educ 2010;74(2):95-103.

7. Hinshaw KJ, Richter LT, Kramer GA. Stress, burnout, and renewal activities of dental hygiene education 7. Hinshaw KJ, Richter LT, Kramer GA. Stress, burnout, and renewal activities
administrators in six US Midwestern States. J Dent Educ 2010;74(3):235-250.

8. Silverstein ST, Kritz-Silverstein D. A longitudinal study of stress in first-year dental students. J Dent Educ 2010;74(8):836-848.

9. Kumar S, Dagli RJ, Mathur A, Jain M, Prabu D, Kulkarni S. Perceived sources of stress among Indian dental students. Eur J Dent Educ 2009;13:39-45. [http://dx.doi.org/10.1111/j.1600-0579.2008.00535.x]
10. Polychronopoulou A, Divaris K. Dental students' perceived sources of stress: A multi-country study. J Dent Educ 2009;73(5):631-639.

11. Gorter R, Freeman R, Hammen S, Murtomaa H, Blinkhorn A, Humphris G. Psychological stress and health in undergraduate dental students: Fifth year outcomes compared with first year baseline results from five European dental schools. Eur J Dent Educ 2008;12:61-68. [http://dx.doi.org/10.1111/j.1600-0579.2008.00468.x]

12. Morse Z, Dravo U. Stress levels of dental students at the Fiji School of Medicine. Eur J Dent Educ 2007;11:99-103 [http://dx.doi.org/10.1111/j.1600-0579.2007.00435.x]

13. Sofola OO, Jeboda SO. Perceived sources of stress in Nigerian dental students. Eur J Dent Educ 2006;10:20-23. [http://dx.doi.org/10.1111/j.1600-0579.2006.00391.x]

14. Gorter RC. Work stress and burnout among dental hygienists. Int J Dent Hyg 2005;3(2):88-92. [http://dx.doi. org/10.1111/j.1601-5037.2005.00130.x]

15. Pohlmann K, Jonas I, Ruf S, Harzer W. Stress, burnout and health in the clinical period of dental education. Eur J Dent Educ 2005;9(2):78-84.[http://dx.doi.org/10.1111/j.1600-0579.2004.00359.x]

16. Polychronopoulou A, Divaris K. Perceived sources of stress among Greek dental students. I Dent Educ 2005;69(6):687-692.

17. Naidu RS, Adams JS, Simeon D, Persad S. Sources of stress and psychological disturbance among dental students in the West Indies. J Dent Educ 2002;66(9):1021-1030.

18. Sanders E, Lushington K. Effect of perceived stress on student performance in dental school. J Dent Educ 2002;66(1):75-81.

19. Heath JR, Macfarlane TV, Umar MS. Perceived sources of stress in dental students. Dent Update 1999;26:94-100.

20. Roberts RA, Ellingson PL. Perceived environmental stressors for dental hygiene students. J Dent Edu 1996;60(10):836-841.

1. Hendricks SJH, Joshi A, Crombie K, Moola MH. Perceived sources of stress among black dental students in South Africa. J Dent Educ 1994;58(6):406-410.

22. Lopresti S. Stress and the oral hygiene profession. Can J Dent Hyg 2014;48(2): 63-69.

23. Humphris G, Blinkhorn A, Freeman R, et al. Psychological stress in undergraduate dental students: Baseline results from seven European dental schools. Eur I Dent Educ 2002-6.22-29. [http.//dx doiorg/10.1034/j1600-0579.2002.060105 x]

4. Psychologists Press, 1996.

25. Scutter S, Goold M. Burnout in recently qualified physiotherapists in South Australia. Austr Physiother 1995;41(2):115-118. [http://dx.doi. org/10.1016/S0004-9514(14)60425-6]

26. Gorter RC, Storm MK, te Brake JHM, Kersten HW, Eijkman MAJ. Outcome of career expectancies and early professional burnout among newly qualified dentists. Int Dent J 2007;57(4):279-285

27. Johnson PM. International profiles of dental hygiene 1987 - 2006: A 21-nation comparative study. Int Dent J 2009;59:63-77.

28. Hamill C. The phenomenon of stress as perceived by Project 2000 student nurses: A case study. J Adv Nursing 1995;21:528-536. [http://dx.doi.org/10.1111/j.1365-2648.1995.tb02737.x]

29. Burk DT, Bender DJ. Use and perceived effectiveness of student support services in a first-year dental student population. J Dent Educ 2005;69(10):1148-1160. 